\title{
Does psychological strengths and subjective well-being predicting parental involvement and problem solving among Malaysian and Indian students?
}

Aqeel Khan*, Roslee Ahmad, Abdul Rahim Hamdan, Mohamed Sharif Mustaffa and Lokman Mohd Tahir

\begin{abstract}
The present study examined the predictors of psychological strengths and subjective well-being for dealing with academic stress perceived by university engineering students. Sample of 400 Malaysian ( $N=180$ boys and $N=220$ girls) age varies 18 to 25 years and 400 Indian students ( $N=240$ boys and $N=160$ girls) age varies 18 to 25 years from public universities were participated. Quantitative method was used for data analysis. Findings shows that gender, religiosity and socioeconomic status are significantly influencing psychological strengths and subjective well-being of both Indian and Malaysian students. Findings also revealed that parental involvement and problem solving coping styles were significantly predicting psychological strengths and subjective well-being among both countries participants. Findings of the current study provide the insight for the educators, and parents dealing with adolescents.
\end{abstract}

Keywords: Psychological strengths; Well-being; Problem solving; Students

\section{Introduction}

Malaysian culture represents diverse multi-ethnic and multi-cultural society (Verkuyten \& Khan 2012; cited in Khan et al. 2014a; Janssens et al. 2014 \& Ghani et al. 2014) and India as well represents multi religious society (Husain et al. 2012). Stresses faced by among Malaysian and Indian students, like academic stress emerges as significant mental health problem in recent years (Chou et al. 2011 \& Rangaswamy 1995; Khan et al. 2014b). In Asian context, parents hope their children will get good grades because it is important in getting a good job. For example, there is an old proverb in Chinese "Everything is unworthy except studying" (cited in Khan 2012). Therefore emerging adolescents grow up believing that academic failure will have negative repercussions, so they are putting immense pressure on themselves to excel in university they were also cognizant to live up to the expectations of parents and teachers (Ang \& Huan 2006). Parental involvement greatly influences subjective

\footnotetext{
* Correspondence: draqeelkhan@gmail.com

Faculty of Education, Universiti Teknologi Malaysia (UTM), Skudai 81310, Johor, Malaysia
}

well-being of the adolescents. Existing researches showed strong relationship of parental involvement and subjective well-being (Dmitrieva et al. 2004; Doyle \& Markiewicz 2005; Gibson \& Jefferson 2006; Wilkinson 2004).

According to Diener et al. (2006), subjective well-being (SWB) may regard as one's evaluations of their own lives, which can be their judgments towards current status quo like life satisfaction and evaluations based on personal feelings (including because of the way they evaluate their lives either as going in a good way or imperfectly. Research on SWB consisted of a worldwide life satisfaction which including positive affect and negative affect (Lightsey 1996; Robbins \& Kliewer 2000). Even though there were many researches had been carried out on the topic of SWB in recent years, there still an overall lack of studies that have examined the experience of SWB in children and adolescents (Lent et al. 2005) moods and inner emotions).

Various studies report that Asians give more priority to academic achievement since it brings career success (Alshemmeri et al. 2011; Gloria \& Ho 2003; Sue \& Okazaki 1990). Utilizing effective coping strategies,

\section{Springer}

(c) 2014 Khan et al.; licensee Springer. This is an Open Access article distributed under the terms of the Creative Commons Attribution License (http://creativecommons.org/licenses/by/4.0), which permits unrestricted use, distribution, and reproduction in any medium, provided the original work is properly credited. 
parental involvement and positive psychological strengths can help alleviate the negative effects of stress (Dressler 1991) and increase the well-being, while deficits in problem-solving behaviors will increase the risk of academic stress. According to Noack and Puscher (1999), high parental support has been associated with positive guidance for emerging adolescent (Khan \& Kalu 2011). Parent support also allow the emerging adolescent to cope better with the transition to adolescent (Scabini et al. 1999).

Present study examines (1) Influence of demographic characteristics on the outcome variables (2) relationship of positive psychological strengths and its dimensions with subjective well-being, parental involvement, problem solving coping and academic stress; and (3) the role of parental involvement and problem solving coping as a predictor of positive psychological strengths and subjective well-being were investigated.

\section{Method \\ Participants}

Firstly informed consent were obtained from the participants and ethical approval granted by university. Survey data were collected from 400 Malaysian engineering students comprising 220 girls and 180 boys between the ages of $18-25$ years (Mage $=20.01$ years, SD $=13.97$ ), residing in Kuala Lumpur and Johor Bahru cities of Malaysia. Another group of participants includes 400 Indian students, 160 girls and 240 boys between the ages of $18-25$ (Mage $=22.01$ years, $S D=15.22$ ), residing in New Delhi city of India.

\section{Measures}

The following measures were used:

Positive psychological strengths questionnaire (PPSQ); (Luthans et al. 2007a). The 24 items of positive psychological strengths with six items of each sub-measure includes self efficacy, hope, optimism and resiliency. The scale items were anchored from "1" (strongly disagree) to "6" (strongly agree). Example of items include "I feel confident helping to set targets/goals in my work area" (confidence); "I can think of many ways to reach my current work goals" (hope); "When things are uncertain for me at work I usually expect the best" (optimism), and "I usually take stressful things at work in stride" (resiliency). Luthans et al. 2007b; alpha $=.88$ ), used to measure the positive psychological strengths (Hope, Optimism, Resiliency and Self- efficacy) with response choices into a 6 -point Likert-type scale $(1=$ strongly disagree, $2=$ disagree, $3=$ somewhat disagree, $4=$ somewhat agree, 5 = agree, $6=$ strongly agree). Reliability coefficients of current study for all the components were reported (Malaysian $\alpha=.84$; Indian $\alpha=87$ ).
Satisfaction with life scale (SWLS); (Diener et al. 1985) consisting 5 items was used to measure the subjective well being. Subjects responded to items using a 7-point Likert scale ranging from $1=$ "strongly disagree" to $7=$ "strongly agree." Responses were summed to produce a total SWLS score, with higher scores indicating more life satisfaction. Internal consistency (.87), test-retest reliability (.82, eight weeks), and validity of the SWLS are good (Diener et al. 1985). The Cronbach's alpha in the present study were observed (Malaysian $\alpha=.93$; Indian $\alpha=85$ ).

Student Academic Stress Scale (Gadzella 1991); The SASS used with four domains: Physiological, Behavioral, Cognitive, and Affective. The Student-life Stress Inventory (SSI) has been used in numerous studies to measure college student stress and to determine the reliability and validity of the instrument (Gadzella 1991, 1994a, 1994b, 2004; Gadzella \& Baloglu 2001). Cronbach's alpha ranging from .52 to .85 . The Cronbach's alpha in the present study were observed (Malaysian $\alpha=.88$; Indian $\alpha=81$ ).

Parental Home Involvement (Nyarko 2008); Measures parental actions such as encouragement of their children to succeed, monitoring of their homework, going on outings with the participants. The scale was measured on a five-point likert scale ranging from 1-almost never to 5-very often. Some of the items on the scale are "My parents discuss my school progress with me", "My parents go on outings with me." In all, seven items were measured on this scale. The alpha coefficients were: Mother $=0.82$ and father $=0.80$. The Cronbach's alpha in the present study were observed (Malaysian $\alpha=.90$; Indian $\alpha=.94$ ).

Adolescent Coping Scale (ACS) (Frydenberg \& Lewis 1993); It consists 6 items Solving the Problem subscale from the short version of ACS. High scores on the Solving the Problem indicate positive coping strategies. Internal consistency of the 18 scales has been reported to have alphas ranging from .45 to .85 . Test retest reliability over a two week period has been shown to be moderate (Frydenberg and Lewis 1993). The Cronbach's alpha in the present study were observed (Malaysian $\alpha=.83$; Indian $\alpha=89$ ).

Demographic variables; Participants gender, marital status, believe in religion or not and socio-economic status were also identified.

Research question 1: What are the influence of gender, socio-economic status, and religiosity on positive psychological strengths and subjective well-being among Malaysian and Indian participants?

Table 1 represents the Influence of demographic characteristics of participants on outcome variables. The F-tests showed significantly higher level of positive psychological strengths among Indian male (Mean $=14.39, \mathrm{SD}=5.98$ ) than Female (Mean $=7.11, \mathrm{SD}=3.44)(\mathrm{F}=19.84, \mathrm{p}<.001)$. 
Table 1 Influence of demographic characteristics of participants on positive psychological strengths

\begin{tabular}{|c|c|c|c|c|c|c|c|c|}
\hline \multicolumn{5}{|c|}{ Positive psychological strengths (Malaysian) } & \multicolumn{3}{|c|}{ Positive psychological strengths (Indian) } & \multirow[b]{2}{*}{$\mathrm{F}$} \\
\hline & $\mathbf{N}$ & Mean & SD & $\mathrm{F}$ & $\mathbf{N}$ & Mean & SD & \\
\hline \multicolumn{9}{|l|}{ Gender } \\
\hline Male & 160 & 7.55 & 2.10 & $6.90^{*}$ & 220 & 14.39 & 5.98 & $19.84^{* *}$ \\
\hline Female & 240 & 4.02 & 0.84 & & 180 & 07.11 & 3.44 & \\
\hline \multicolumn{9}{|l|}{ Religiosity } \\
\hline Religious & 286 & 8.17 & 2.96 & $17.14^{* *}$ & 270 & 15.05 & 2.96 & $21.02^{* *}$ \\
\hline Non-Religious & 114 & 5.08 & 1.18 & & 130 & 9.78 & 3.25 & \\
\hline \multicolumn{9}{|l|}{ Socio-economic status } \\
\hline Belong to Wealthier Family & 230 & 8.98 & 2.45 & $19.25^{* *}$ & 267 & 18.05 & 6.20 & $07.97^{*}$ \\
\hline Belong to Poor Family & 170 & 5.25 & 1.98 & & 133 & 06.45 & 2.05 & \\
\hline
\end{tabular}

${ }^{*}$ sig at $.05 ;{ }^{* *}$ sig at .001 level.

There were significantly higher level of positive psychological strengths among participants of non- religious group (Mean $=15.05, \mathrm{SD}=2.96$ ) than religious group (Mean $=9.78, \mathrm{SD}=3.25),(\mathrm{F}=21.02, \mathrm{p}<.001)$. There were significantly higher level of positive psychological strengths among participants belong to wealthier families (Mean $=18.05, \mathrm{SD}=6.20$ ) than belong to poor families (Mean $=6.45, \mathrm{SD}=2.05),(\mathrm{F}=7.97 . \mathrm{p}<.05)$.

Among Malaysian male participants' positive psychological strengths are higher level (Mean $=7.55, \mathrm{SD}=2.10)$ than Female (Mean $=4.02, \mathrm{SD}=.84)(\mathrm{F}=6.95, \mathrm{p}<.05)$. There are significantly higher level of positive psychological strengths among participants of religious group (Mean $=8.17, \mathrm{SD}=2.96$ ) than non-religious group (Mean $=5.08, \mathrm{SD}=1.18),(\mathrm{F}=17.14, \mathrm{p}<.001)$. There are significantly higher levels of positive psychological strengths among participants belong to wealthier families (Mean $=8.98, \mathrm{SD}=5.25$ ) than participants belong to poor families (Mean $=5.25, \mathrm{SD}=1.98),(\mathrm{F}=19.25, \mathrm{p}<.001)$.

Table 2 represents the Influence of demographic characteristics of participants on subjective well-being. The
F-tests shows significantly higher level of subjective well-being among Indian male (Mean $=14.39, \mathrm{SD}=5.98$ ) than Female (Mean $=7.11, \mathrm{SD}=3.44),(\mathrm{F}=19.84, \mathrm{p}<.001)$. There are significantly higher levels of subjective well-being among participants of religious group (Mean $=15.05, \mathrm{SD}=2.96$ ) than non-religious group (Mean $=9.78, \mathrm{SD}=3.25),(\mathrm{F}=21.02, \mathrm{p}<.001)$. There are significantly higher level of subjective well-being among participants belong to wealthier families (Mean $=18.05, \mathrm{SD}=6.20)$ than poor families (Mean $=6.45$, $\mathrm{SD}=2.05),(\mathrm{F}=7.97, \mathrm{p}<.01)$.

Among Malaysian male participants' subjective wellbeing are higher (Mean $=7.55, \mathrm{SD}=2.10$ ) than female (Mean $=4.02, \mathrm{SD}=.84),(\mathrm{F}=6.95, \mathrm{p}<.01)$. There are significantly higher levels of subjective well-being among participants of religious group (Mean $=8.17, \mathrm{SD}=2.96$ ) than non-religious group (Mean $=5.08, \mathrm{SD}=1.18),(\mathrm{F}=17.14$, $\mathrm{p}<.001)$. There are significantly higher level of subjective well-being among participants belong to wealthier families $($ Mean $=8.98, \mathrm{SD}=5.25)$ than poor families $($ Mean $=5.25, \mathrm{SD}=1.98),(\mathrm{F}=19.25, \mathrm{p}<.001)$.

Table 2 Influence of demographic characteristics of participants on subjective well-being

\begin{tabular}{|c|c|c|c|c|c|c|c|c|}
\hline \multicolumn{5}{|c|}{ Subjective well-being (Malaysian) } & \multicolumn{4}{|c|}{ Subjective well-being (Indian) } \\
\hline & $\mathrm{N}$ & Mean & SD & $\mathrm{F}$ & $\mathbf{N}$ & Mean & SD & $\mathrm{F}$ \\
\hline \multicolumn{9}{|l|}{ Gender } \\
\hline Male & 160 & 7.55 & 2.10 & $6.95^{*}$ & 220 & 14.39 & 5.98 & $19.84^{* *}$ \\
\hline Female & 240 & 4.02 & 0.84 & & 180 & 07.11 & 3.44 & \\
\hline \multicolumn{9}{|l|}{ Religiosity } \\
\hline Religious & 286 & 8.17 & 2.96 & $17.14^{* *}$ & 270 & 15.05 & 2.96 & $21.02^{* *}$ \\
\hline Non-Religious & 114 & 5.08 & 1.18 & & 130 & 9.78 & 3.25 & \\
\hline \multicolumn{9}{|l|}{ Socio-economic status } \\
\hline Belong to Wealthier Family & 230 & 8.98 & 2.45 & $19.25^{* *}$ & 267 & 18.05 & 6.20 & $07.97^{* *}$ \\
\hline Belong to Poor Family & 170 & 5.25 & 1.98 & & 133 & 06.45 & 2.05 & \\
\hline
\end{tabular}

*sig at $.05 ;{ }^{* *}$ sig at .001 level. 
Research question 2: what are the relationship of independent and outcome variables among Malaysian and Indian participants?

Table 3 presents mean, Cronbach's alpha reliability and intercorrelation matrix of the studied variables. Cronbach's alpha reports that all variables are reliable from range .81 to .94. Most of the variables are positively correlated with each other except academic stress is negatively correlated with positive psychological strengths, subjective well-being, parental involvement, and problem solving. Based on the results of Malaysians, parental involvement had the positive correlation with problem solving coping with the coefficient of .41. On the other hand, for Indians participants, parental involvement also had the positive correlation with problem solving coping with the coefficient .32.

Research question 3: What are the role of parental involvement and problem solving coping as a predictor of positive psychological strengths and subjective well-being? Tables 4 and 5 reports regression model to test the hypothesis that gender, religiosity, socioeconomic status, parental involvement and problem solving significantly predicts positive psychological strengths and subjective well-being.

Table 4 shows regression results that there is 35\% of the variation exists in positive psychological strengths and $39 \%$ of the variation in subjective well-being can be explained including problem solving, parental involvement and demographic variables for Malaysian participants.

Table 5 shows $27 \%$ of the variation in positive psychological strengths and $38 \%$ of the variation in subjective well-being explained by problem solving, parental involvement and demographic variables for Indian participants.
Table 4 Regression model predicting positive psychological strengths and subjective well-being for Malaysian participants

\begin{tabular}{lccccccc}
\hline & \multicolumn{3}{c}{ Model 1 } & & \multicolumn{3}{c}{ Model 2 } \\
\cline { 2 - 3 } Predictors & $\mathbf{B}$ & Std. Error & $\mathbf{R}^{\mathbf{2}}$ & & $\mathbf{B}$ & Std. Error & $\mathbf{R}^{\mathbf{2}}$ \\
\hline Gender & $.294^{*}$ & .113 & & $.263^{*}$ & .193 & \\
Religiosity & $.372^{* *}$ & .106 & & $.248^{*}$ & .112 & \\
Socioeconomic & & & & & & & \\
Status & $.402^{* *}$ & .110 & & $.439^{* *}$ & .131 & \\
Parental Involvement & $.422^{* *}$ & .163 & .35 & $.632^{* *}$ & .147 & .39 \\
Problem Solving & $.387^{* *}$ & .177 & & $.432^{* *}$ & .116 & \\
\hline
\end{tabular}

* p $\backslash 0.05$ *** p 0.01 .

Model 1 Dependent Variable: Positive Psychological Strengths.

Model 2 Dependent Variable: Subjective Well-Being.

\section{Discussion}

Research findings declared higher positive psychological strengths and subjective well-being found for those who were: male, non-religious, and wealthy families of Indian subcontinent participants. Based on the analyzed results, Indian male were experiencing higher level of positive psychological strengths than Indian female. Previous studies revealed Indian female reported restriction in exposed to outside environment and they are also restricted to direct their feelings (Singh \& Udainiya 2009). Which clearly indicates that Indian women still discouraged and reflecting deprived part of the society. This explains why Indian women not holding positive attitudes towards oneself than their male counterpart (As cited Khan 2013, p1290). Malaysian and Indian religious participants are scored significantly higher levels of positive psychological strengths and subjective well-being than non-religious group. Finding of Indian and Malaysian families conveyed significantly higher level of positive psychological strengths

Table 3 Means and intercorrelations of independent and outcome variables

\begin{tabular}{|c|c|c|c|c|c|c|c|}
\hline Variable & $\mathbf{M}$ & A & 1 & 2 & 3 & 4 & 5 \\
\hline \multicolumn{8}{|l|}{ Malaysians $(n=400)^{*}$} \\
\hline 1. Positive psychological strengths & 11.08 & .84 & 1 & & & & \\
\hline 2. Subjective well-being & 12.57 & .93 & $.23^{* *}$ & 1 & & & \\
\hline 3. Parental involvement & 16.28 & .90 & $.27^{* *}$ & $.34^{*}$ & 1 & & \\
\hline 4. Problem solving & 14.33 & .83 & $.33^{* *}$ & $.21^{*}$ & $.41^{*}$ & 1 & \\
\hline 5. Academic stress & 6.87 & .88 & -.43 & -.21 & -.31 & -.13 & 1 \\
\hline \multicolumn{8}{|l|}{ Indians $(n=400)^{*}$} \\
\hline 1. Positive psychological strengths & 12.99 & .87 & 1 & & & & \\
\hline 2. Subjective well-being & 18.42 & .85 & $.44^{* *}$ & 1 & & & \\
\hline 3. Parental involvement & 14.54 & .94 & $.22^{*}$ & $.23^{*}$ & 1 & & \\
\hline 4. Problem solving & 15.36 & .89 & $.24^{* *}$ & $.29 * *$ & $.32^{* *}$ & 1 & \\
\hline 5. Academic stress & 09.41 & .81 & -.06 & -.12 & -.10 & .14 & 1 \\
\hline
\end{tabular}

${ }^{*}$ sig at $.05 ;{ }^{* *}$ sig at .001 level. 
Table 5 Regression model predicting positive psychological strengths and subjective well-being for Indian participants

\begin{tabular}{lccccccc}
\hline & \multicolumn{3}{c}{ Model 1 } & & \multicolumn{3}{c}{ Model 2 } \\
\cline { 2 - 3 } \cline { 5 - 7 } Predictors & $\mathbf{B}$ & Std. error & $\mathbf{R}^{\mathbf{2}}$ & & $\mathbf{\beta}$ & Std. error & $\mathbf{R}^{\mathbf{2}}$ \\
\hline Gender & $.284^{*}$ & .125 & & $.347^{*}$ & .112 & \\
Religiosity & $.363^{* *}$ & .118 & & $.233^{*}$ & .132 \\
Socioeconomic & & & & & & \\
Status & $.443^{* *}$ & .166 & & & & \\
Parental involvement & $.433^{* *}$ & .164 & .27 & $.665^{* *}$ & .122 & .38 \\
Problem solving & $.298^{* *}$ & .131 & & $.254^{* *}$ & .123 & \\
\hline
\end{tabular}

*p $\backslash 0.05 ;{ }^{* *} p \backslash 0.01$

Model 1 Dependent Variable: Positive Psychological Strengths.

Model 2 Dependent Variable: Subjective Well-Being.

among participants who belong to wealthier families than belong to poor families (Diener et al. 1999).

Findings show higher positive psychological strengths and subjective well-being for those who were: women, religious, and wealthy families of Malaysian subcontinent participants. Based on these findings which clearly showing that Malaysian Muslim culture rapidly changing the societal view and females are not feeling restricted and they are holding positive attitudes towards oneself, getting involved in friendship, having autonomous thought and actions, have the ability to manage complex environments to suit personal needs and values, recognizing life purpose, and continue developing their strengths. However, since Malaysia's independence in 1957, women's entry into the paid labor force has been dramatic, from $30.8 \%$ in 1957 to $47.1 \%$ in 1995 (Seventh Malaysia Plan, 1996-2000). The main reasons can be explained as (a) greater educational opportunities for women; (b) the implementation of the New Economic Policy by the government in 1969; and (c) the rapid economic development and industrialization, which have created jobs for women within the laborintensive industries, such as electronics and textiles. Therefore education provides an opportunity among Malaysian women in breaking their barrier of success. Women are, in this broadened perspective, not passive recipients of welfare-enhancing help brought about by society, but are active promoters and facilitators of social transformations. Such transformations influence, of course, the lives and well-being of Malaysian women.

Religiosity also considered important determinant for deriving well-being (Stavrova et al. 2013; Ellison et al. 2009; Kim 2003; Ventis 1995). Religious Malaysian women reported higher level of positive psychological strengths than non-religious group (Khan 2013). Frey and Stutzer (2002) reported strong link of religion and life satisfaction because of the mosque attendance provide opportunity to develop social support network, which instill meaning and purpose in life and this may give higher ability to fight negative life challenges. It has been found by Folkman (2008) religious commitment gives meaning in life, purpose, satisfaction and hope in life.

Positive psychological strengths were found to improved subjective well-being of the adolescents. Likewise, previous research by (Khan and Husain 2010) revealed significant positive relationship between positive psychological strengths and subjective well-being. Apart from that, current finding recommends that problem solving, parental home involvement, gender, socio-economic status, and religiosity of the participants does contribute and have significant influence on positive psychological strengths and subjective well-being. Earlier studies showed that demographic characteristics of the country like gender (Fujita et al. 1991), religiosity (Frey and Stutzer 2002) and socio-economic status were found to be strong predictors of one's life satisfaction (Bradleya and Corwyna 2004).

Current findings strongly suggest parental involvement was the strongest predictor of positive psychological strengths and subjective well-being (Flouri \& Buchanan 2003) among Indian and Malaysian participants. Parents considered children's best supporter as both of them their child's nearest kith and kin. Aunola et al. (2003) declared that a parent's belief in his or her child's academic success deeply affected in child's success and drive to do extremely well. Epstein (2005) suggested understanding in the interaction of parenting skills, student success and commitment to communication consistently influence in student progress. Present research proved that parental involvement improved student well-being (Epstein 2005).

One of the limitations of the study was that the participants were selected from two cities of each country, which may not be representative of a country as a whole. This study was limited by its reliance on small sample, therefore future research on larger and more diverse samples are required for determining the generalizability of the findings. In addition the measure used in this study although it appears to be valid and reliable instruments, more research is necessary to verify this.

\section{Ethics statement}

All measurements have been carried out on human being complying with local laws.

\section{Competing interests}

The authors declare that they have no competing interests.

\section{Authors' contributions}

AK conceived and designed the study, carried out the fieldwork, data analyses and interpretation results with discussion. ARH, RA, MSM and LMT collaborated in drafting the literature review. All authors read and approved the final manuscript. 


\section{Acknowledgments}

Fieldwork was conducted with the financial support of the Ministry of Higher Education (MOHE) and Universiti Teknologi Malaysia (UTM).

\section{Received: 22 April 2014 Accepted: 29 October 2014} Published: 19 December 2014

\section{References}

Alshemmeri F, Putih A, Siraj S, Khan A, Abdallah N (2011) Art ability and academic achievement in the Kingdom of Saudi Arabia: role of age and sex. New Educ Rev 26(4):238-247

Ang RP, Huan VS (2006) Relationship between academic stress and suicidal ideation: testing for depression as a mediator using multiple regressions. Child Psychiatry Hum Dev 37:133-143

Aunola K, Nurmi J, Lerkkanen M, Rasku-Puttonen H (2003) The roles of achievementrelated behaviors and parental beliefs in children's mathematical performance. Educ Psychol 23(4):403-421

Bradleya R, Corwyna R (2004) Life satisfaction among European American, African American, Chinese American, Mexican American, and Dominican American adolescents. Int J Behav Dev 28(5):385-400

Chou KL, Wong WKF, Chow NWS (2011) Interaction between pre- and post-migration factors on depressive symptoms in new migrants to Hong Kong from Mainland China. Community Ment Health J 47(5):560-567

Diener E, Emmons RA, Larson RJ, Griffin S (1985) The satisfaction with life scale. J Pers Assess 49:71-75

Diener E, Suh EM, Lucas RE, Smith HL (1999) Subjective well-being: three decades of progress. Psychol Bull 125:276-302

Diener E, Lucas R, Scollon CN (2006) Beyond the hedonic treadmill: revising the adaptation theory of well-being. Am Psychol 61:305-314

Dmitrieva J, Chen C, Greenberger E, Gil-Rivas V (2004) Family relationships and adolescent psychosocial outcomes: converging findings from eastern and western cultures. J Res Adolesc 14:425-447

Doyle AB, Markiewicz D (2005) Parenting, marital conflict and adjustment from early- to mid-adolescence: mediated by adolescent attachment style? Youth Adolesc 34:97-110

Dressler WW (1991) Stress and Adaptation in the Context of Culture: Depression in a Southern Black Community. State University of New York Press, Albany, NY

Ellison CG, Burdette AM, Hill TD (2009) Blessed assurance: religion, anxiety, and tranquility among US adults. Soc Sci Res 38:656-667

Epstein $J$ (2005) School-initiated family and community partnerships. In: Erb T (ed) This We Believe in Action: Implementing Successful Middle Level Schools. National Middle School Association, Westerville, OH, pp 77-96

Flouri E, Buchanan A (2003) The role of father involvement and mother involvement in adolescents' psychological well-being. Br J Soc Work 33:399-406

Frey B, Stutzer A (2002) Happiness and Economics. How the Economy and Institutions Affect Human Well-being. Princeton University Press, Princeton and Oxford

Frydenberg E, Lewis R (1993) Adolescent Coping Scale. Australian Council for Educational Research, Melbourne

Fujita F, Diener E, Sandvik E (1991) Gender differences in negative affect and well-being: the case for emotional intensity. J Pers Soc Psychol 61:427-434

Gadzella BM (1991) Student-life stress inventory. Author, Commerce, TX

Gadzella BM (1994a) Locus of control differences among stress groups. Percept Mot Skills 79:1619-1624

Gadzella BM (1994b) Student-life Stress Inventory: identification of and reactions to stressors. Psychol Rep 74(2):395-402

Gadzella BM (2004) Three stress groups on their stressors and reactions to stressors in five studies. Psychol Rep 94:562-564

Gadzella BM, Baloglu M (2001) Confirmatory factor analysis and internal consistency of the student-life stress inventory. J Instr Psychol 28(2):84-94

Ghani FA, Latif AA, Aziz AA, Khan A (2014) Validity and reliability analysis of the 'SayangKU' (MyLove) in intervention for addressing adolescents involved in free sex. J Relig Health. doi:10.1007/s10943-014-9935-y

Gibson DM, Jefferson RN (2006) The effect of perceived parental involvement and the use of growth-fostering relationships on self-concept in adolescents participating in gear up. Adolescence 41:111-125

Gloria AM, Ho TA (2003) Environmental, social, and psychological experiences of Asian-American undergraduates: examining issues of academic persistence. J Couns Dev 81:93-106
Husain A, Rahman S, Khan A (2012) Human values- a running commentary based on literary texts. Man In India 92(3-4):491-504

Janssens H, Verkuyten M, Khan A (2014) Perceived social structural relations and group stereotypes: a test of the stereotype content model in Malaysia. Asian J Soc Psychol. doi:10.1111/ajsp.12077

Khan A (2012) Sex differences' in educational encouragement and academic achievement. Psychol Rep 111(1):149-155

Khan A (2013) Predictors of positive psychological strengths and subjective wellbeing among North Indian adolescents: role of mentoring and educational encouragement. Soc Indicators Res 114:1285-1293

Khan A, Husain A (2010) Social support as the moderator of positive psychological strengths and subjective well-being. Psychol Rep 106(2):534-538

Khan A, Kalu OC (2011) Psychology and counseling responsibilities for continuous assessment in Malaysian school system. Sci Res Essays 6 (11):2259-2263

Khan A, Ahmad R, Hamdan RA, Mustaffa MS (2014a) Educational encouragement, parenting styles, gender and ethnicity as predictors of academic achievement among special education children. Int Educ Stud 7(2):18-24

Khan A, Hamdan RA, Ahmad R, Mustaffa MS (2014b) Mentoring in Indian youth challenges. Man In India 94(1-2):265-269

Kim AE (2003) Religious influences on Personal and societal well-being. Soc Indicators Res 62:149-170

Lent RW, Singley D, Sheu H, Gainor KA, Brenner BR, Treistman D, Ades L (2005) Social cognitive predictors of domain and life satisfaction: exploring the theoretical precursors of subjective well-being. J Couns Psychol 52(3):429-442

Lightsey OR (1996) What leads to wellness? The role of psychological resources in well being. Couns Psychol 24(4):589-735

Luthans F, Youssef CM, Avolio BJ (2007a) Psychological Capital. Oxford University Press, New York, pp 237-238

Luthans F, Youssef CM, Avolio BJ (2007b) Psychological Capital. Oxford University Press, New York, pp 237-238

Folkman S (2008) The case for positive emotions in the stress process. Anxiety Stress Coping 21(1):3-14

Noack P, Puscher B (1999) Differential trajectories of parent-child relationships and psychosocial adjustment in adolescents. J Adolesc 22:795-804

Nyarko K (2008) Parental Involvement: A Sine Qua Non in Adolescents' Educational Achievement. http://edoc.ub.uni-muenchen.de/8384/1/ Nyarko_Kingsley.pdf

Rangaswamy K (1995) Editorial: academic stress and mental health. Ind J Clin Psychol 22:1-2

Robbins SB, Kliewer WL (2000) Advances in theory and research on subjective well-being. In: Brown SD, Lent RW (ed) Handbook of Counseling Psychology, 3rd edition. John Wiley \& Sons, Inc, New York, NY, pp 310-345

Scabini E, Lanz M, Marta E (1999) Psychosocial adjustment and family relationships: a typology of Italian families with a late adolescent. J Youth Adolesc 28:633-644

Singh B, Udainiya R (2009) Self-efficacy and well-being of adolescents. J Indian Acad Appl Psychol 35(2):227-232

Stavrova O, Fetchenhauer D, Schlösser T (2013) Why are religious people happy? The effect of the social norm of religiosity across countries. Soc Sci Res 42:90-105

Sue S, Okazaki S (1990) Asian-American educational achievements: a phenomenon in search of an explanation. Am Psychol 45:913-920

Ventis WL (1995) The relationships between religion and mental health. J Soc Issues 51:33-48

Verkuyten M, Khan A (2012) Interethnic relations in Malaysia: group identifications, indispensability and inclusive nationhood. Asian J Soc Psychol 15(2):132-139

Wilkinson RB (2004) The role of parental and peer attachment in the psychological health and self-esteem of adolescents. J Youth Adolesc 33:479-493

\section{doi:10.1186/2193-1801-3-756}

Cite this article as: Khan et al:: Does psychological strengths and subjective well-being predicting parental involvement and problem solving among Malaysian and Indian students? SpringerPlus 2014 3:756. 